\title{
Fabrication and Characterization of Organic-Inorganic (Orange Dye-Vanadium Oxide) Composite Based Humidity Sensors
}

\author{
Muhammad Tariq Saeed Chani ${ }^{1 *}$, Kh. S. Karimov ${ }^{2,3}$, Abdullah M. Asiri ${ }^{1,4}$ \\ ${ }^{1}$ Department of Chemistry, Faculty of Science, King Abdulaziz University, Jeddah 21589, P.O. Box \\ 80203, Saudi Arabia \\ ${ }^{2}$ GIK Institute of Engineering Sciences and Technology, Topi, District Swabi, KPK, 23640, Pakistan \\ ${ }^{3}$ Center for Innovative Development of Science and Technologies of Academy of Sciences, Rudaki \\ Ave., 33, Dushanbe, 734025, Tajikistan \\ ${ }^{4}$ Center of Excellence for Advanced Materials Research (CEAMR), King Abdulaziz University, \\ Jeddah 21589, P.O. Box 80203, Saudi Arabia \\ *E-mail: tariqchani1@gmail.com
}

doi: $10.20964 / 2017.02 .59$

Received: 3 October 2016 / Accepted: 21 December 2016 / Published: 30 December 2016

The orange dye-vanadium oxide $\left(\mathrm{OD}-\mathrm{V}_{2} \mathrm{O}_{5}\right)$ composite films were deposited from their aqueous suspension at various gravity conditions: at normal (positive) gravity $(+1 \mathrm{~g})$ and negative gravity $(-1 \mathrm{~g})$ by drop casting on to the surface type substrates having silver electrodes which were deposited by vacuum thermal evaporation. The aqueous suspension was prepared by dissolving and mixing OD and $\mathrm{V}_{2} \mathrm{O}_{5}$ in a distilled water with $2: 1 \mathrm{wt} \%$, respectively. The area of each silver electrode was $5 \times 5 \mathrm{~mm}^{2}$ and the gap between two electrodes was $30 \mu \mathrm{m}$, while the thickness of composite films was $10 \mu \mathrm{m}$. The effect of humidity on electrical parameters (capacitance and impedance) of the films were studied and it was observed that with rising humidity the impedance of all the samples decreased up to 30333 times while the capacitance increased up to 2000 times. The samples deposited at $+1 \mathrm{~g}$ showed more sensitivity $(-2.6 \mathrm{M} \Omega / \% \mathrm{RH})$ towards humidity as compared to samples deposited at $-1 \mathrm{~g}(-1.89$ $\mathrm{M} \Omega / \% \mathrm{RH})$. These results are explained by influence of positive and negative gravity, surface tension forces and composition of the solution on the film formation.

Keywords: Organic semiconductor; Orange dye-vanadium oxide composite; drop-casting; gravity method; humidity sensing.

\section{FULL TEXT}

(C) 2017 The Authors. Published by ESG (www.electrochemsci.org). This article is an open access article distributed under the terms and conditions of the Creative Commons Attribution license (http://creativecommons.org/licenses/by/4.0/). 